\title{
مسؤولية شركات الصناعة البترولية اتجاه البيئة
}

رشيد سالمي 1*

ا جامعة المدية؛ الجزائر

Received: 24 May 2015 / Accepted: 17 August 2015

*Corresponding author: profsalmi@yahoo.fr

ملخص

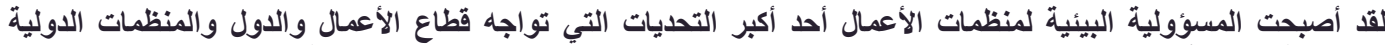

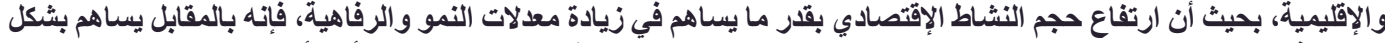

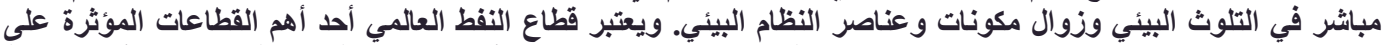

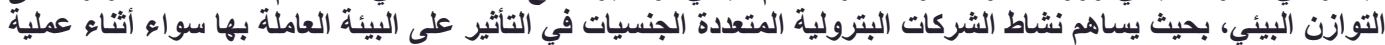

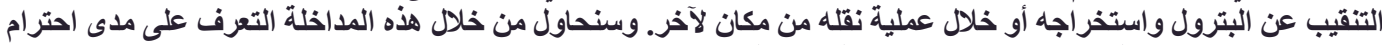

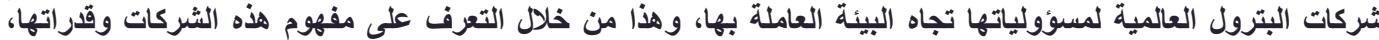

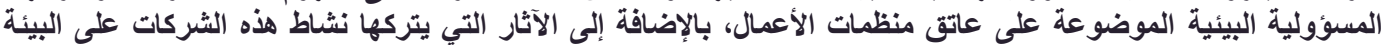

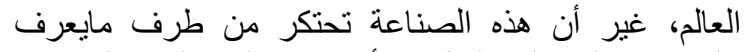

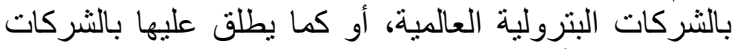

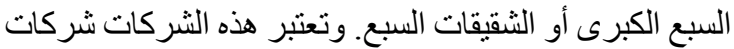

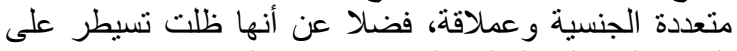

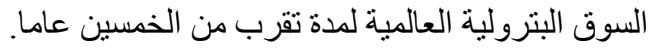

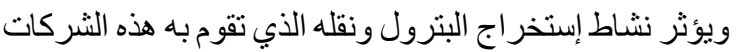

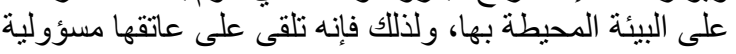

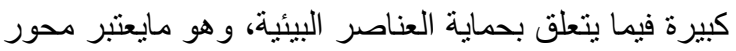
دراستتا، وعليه فقد صغنا الإشكالية الرئيسية لهذه الئية الدراسة كمايلي:

\section{مامدى تحمل شركات الصناعة البترولية اتجاه البيئة بامد}

وتحت هذه الإشكالية الرئيسية ندرج الأسئلة الفرعية التالية:

\section{مقامة}

تعتبر الصناعة البترولية من أهم الصناعات المشكلة للعلاقات الإقتصادية و التجارية الدولية، وينتشر النفط الهي في مناطق معينة فقط من العالم، ويشكل أهم موارد الطاقة بالآلنسبة للاقتصاد

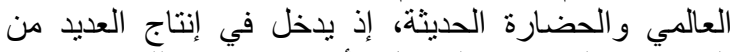

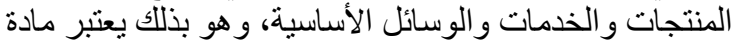

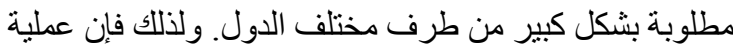

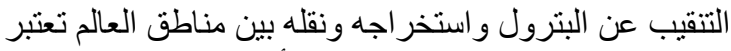

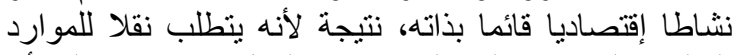

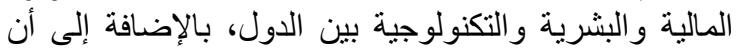

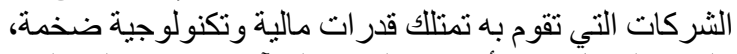

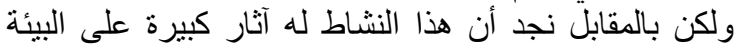

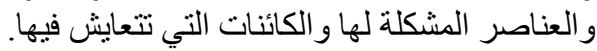

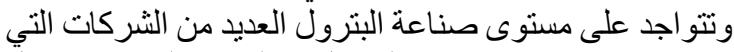
تمارس نشاطات إستخر اج البترول ونقله في العديد من دول 


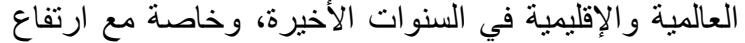

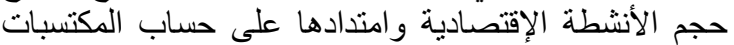

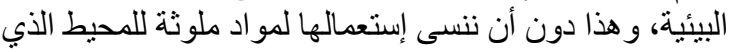

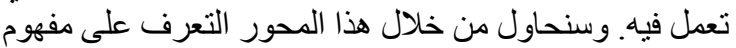

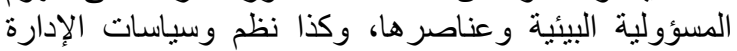
البيئية في منظمات الأعمال. ت البئه

ـ ـ ا مفهوم و عناصر المسؤولية البيئية

لقد أصبح قطاع الأعمال عاملا حاسما في التأثنر على الأداء

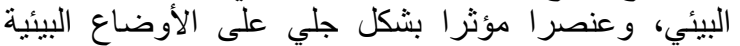

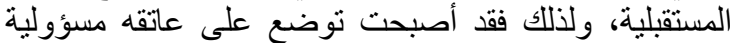
كبيرة في حماية البيئة و عناصر ها.

1 ـ ـ ـ ـ مفهوم المسؤولية البيئية لمنظمات الأعمال

نظر اللتأثير الكبير الذي تمارسه أنشطة الثركات والمؤسسات

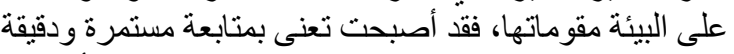

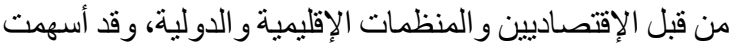

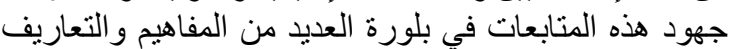

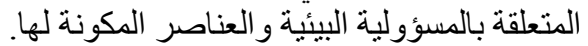

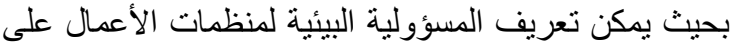

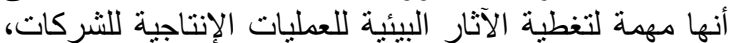

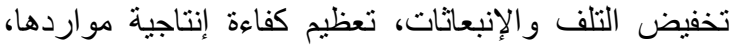

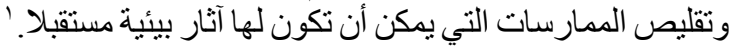

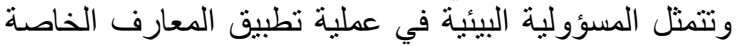

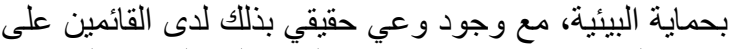
اتخاذ القرارات. ويرتكز تطبيق المسؤولية البيئية على كافة الئي

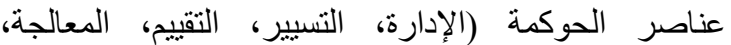

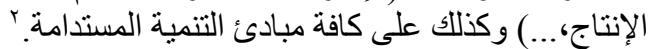

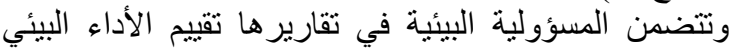

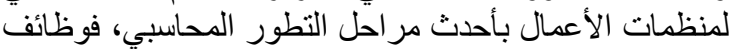

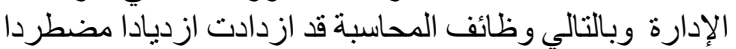

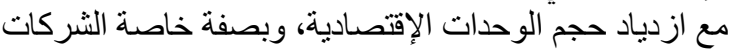
المساهمة. المباد

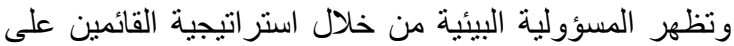

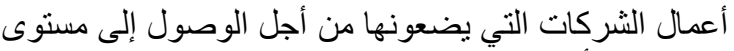

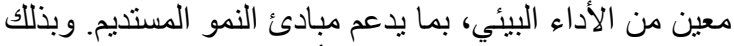

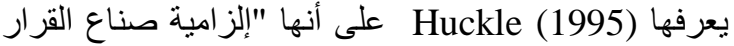
على وضع قرارات تسمح بحماية وتحسين سلامة البيئة، واتخاذها ضمن اهتمامتهم الأولية.

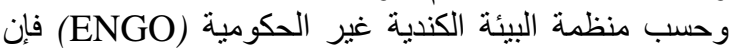

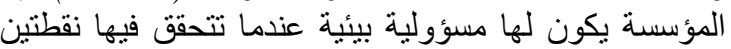

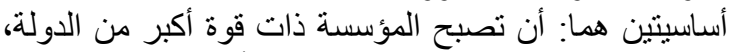
وبذلك يصبح لها مسؤولية تجاه المجتمع، أما النقطة الثانية فهي

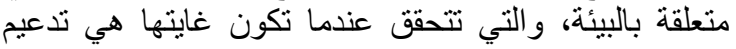

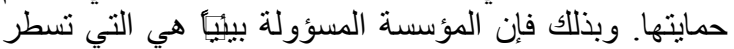

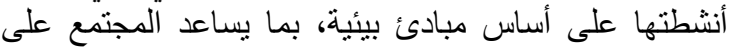
المحافظة عليها. وبذلك يمكن تعريف المسؤولية البيئية الموضو عة على عاتق

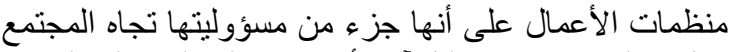

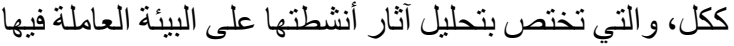

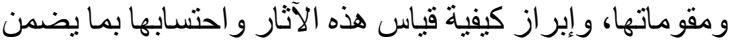
تحمل المؤسسة لها وحماية العناصر البيئية منها بالتبعية.
ماهو مفهوم المسؤولية البيئية وماهي أبعادها؟

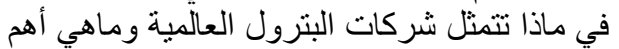
إستر اتيجياتها؟ ماذا لتئ ماهي الآثار التي يتركها نشاط شئر التركات البترول

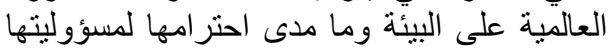
البيئية؟

\section{فرضيات الاراسة:}

لقد وضعنا لهذه الدراسة فرضية واحدة لاختبار صحتها من

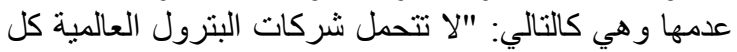

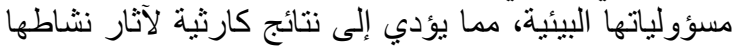

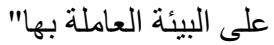

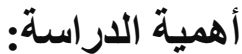

يمكن أن نشتق أهمية هذه الدر اسة من النقاط التالية:

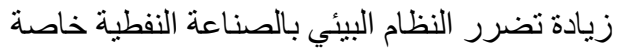

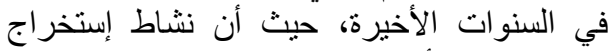
البثرول ونقله أصبح يؤثر بشكل سلبي على الإنى البيئة

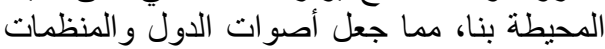

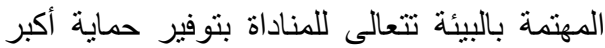

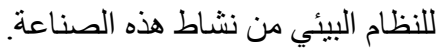

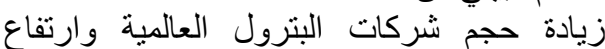

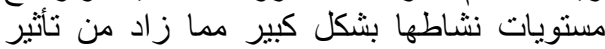

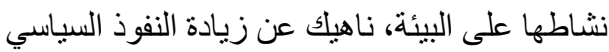

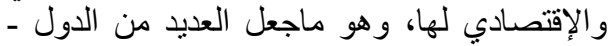
خاصة الدول الناميةـ تتخاضى عن أضئ أضر ار ها البيئية.

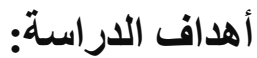

نهذف من ور اء القيام بهذه الدراسة إلى إبراز الآثار البيئية التي

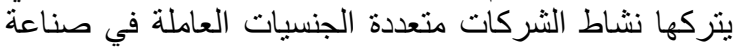
النفط العالمية، و التعرف على كدى مدى تحملها لمسؤوليتها الحمائية

تجاه البيئية.

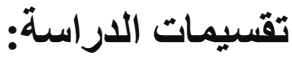

و ون أجل الإحاطة بهذا الموضوع فقد قمنا بتقسيم خطة دراستتا إلى ثلاثة محاور رئيسية كمايلي:

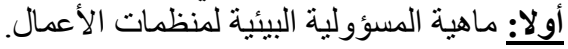

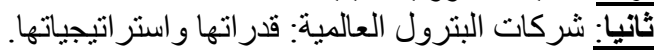

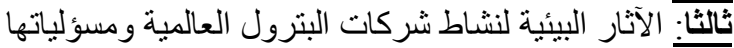
تجاه البيئة. ا ـ ماهية المسؤولية البيئية لمنظمات الأعمال

تمثل المسؤولية البيئية عنصرا من عناصر المسؤولية

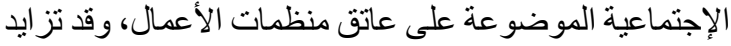
الإهتمام بهذا الموضوع كثيرا من قبل الدول عنو والمنظمات 
ومكونات السياسات و الأنظمة البيئية التي يمكن أن تتنهجها منظمات الأعمال من أجل المحافظة على التثروة البيئية.

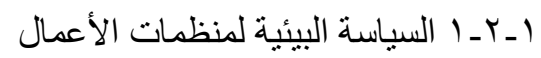

توجب المسؤولية البيئية على المؤسسة وضع وتطوير نظرة

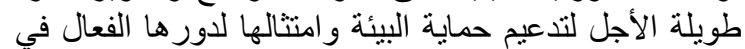

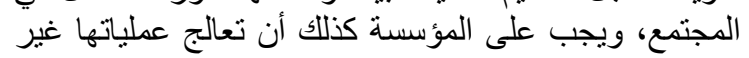

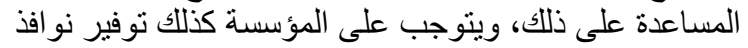

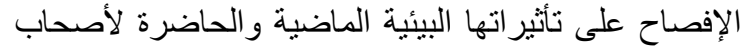
المصنالح في المجتمع.

وتتمثل السياسة البيئية في إعلان إدارة المؤسسة لتعهداتها و التزاماتها تجاه البيئة، ويجب أنئ أن تكون السياسة البيئية أساسا

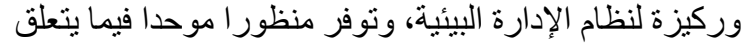

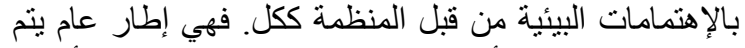

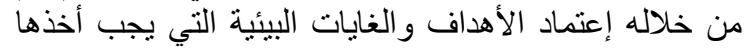

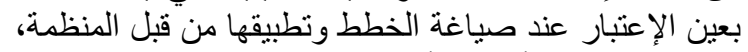

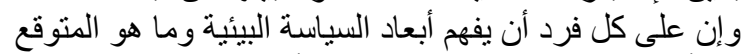

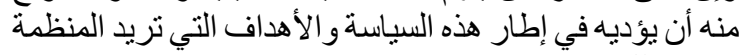
تحقيقها.

ويهدف إعلان "ريو دي جانيرو" بو 199 إلى إقامة شراكة

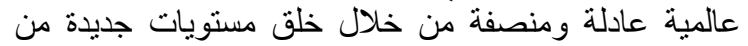

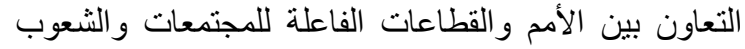

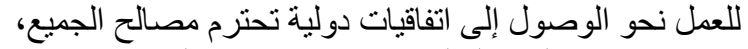

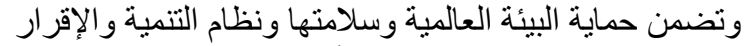

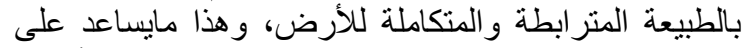
تسطير السياسات الكلية الجزئية التي تسمح بتوفير وهماية الفئر أفضل

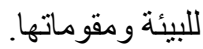

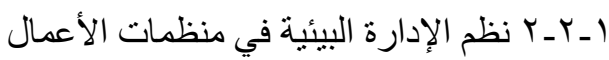
من بين الأنظمة التي يمكن أن تتبناه منظمات الأعمال يمكن أن

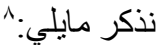

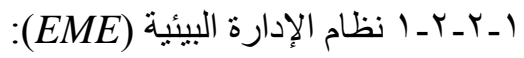

و هو عبارة عن دورة مستمرة للتخطيط و التطبيق و المر اجعة

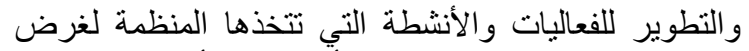

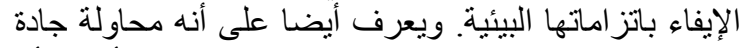

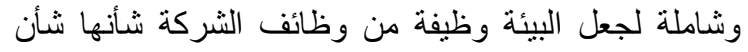

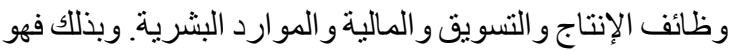
نظام يقابل المكافئ البيئي للنظام الإنتاجي في وظيفة اللئة الإنتاج

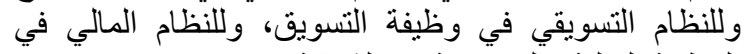
الوظيفة المالية وآلمحأسبية في الثركة.

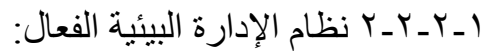

هو نظام مبني على مفهوم الـ TQM لتحسين الإدارة البيئية،

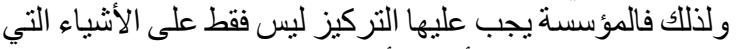

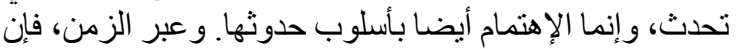

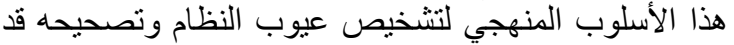

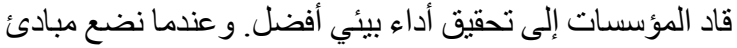
الـ TQM موضع التطبيق الفعلي، فإن منطقة الإهتمام البيئي تقع ضمن مسؤولية الإدارة العليا.

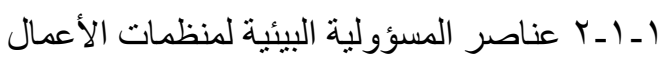

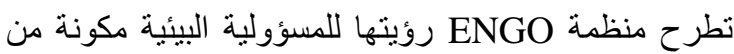

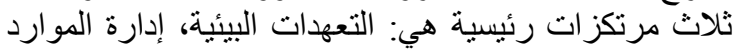

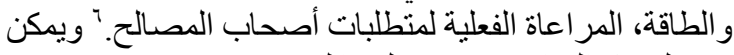
تفصيل هذه العناصر من خلال مايلي:

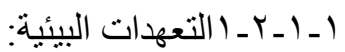

وتكون المؤسسة ذات مسؤولية بيئية إذا حققت مايلي: • • تبني رؤية مؤسسية شاملة بهدف دعم حماية البيئية؛

إنخاذ حماية البيئة والمحافظة عليها كاستراتيجية

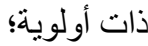

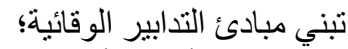
العمل على أساس أن العطليات الإقتصادية تكون

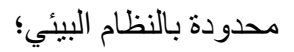

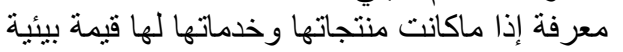
و /أو إجتماعية ومراعاة هذه الخاصية عند اتخاذ

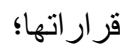

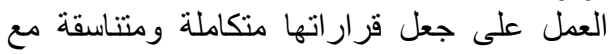
الإجر اءات الحكومية؛

تلتجيئ الثقافة المؤسسية التي تسمح بتدعيم القيم

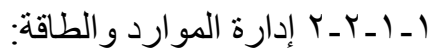
وفي هذا الإطار يمكن ذكر النقاط التالية:

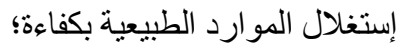

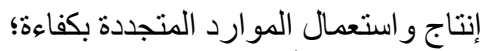
إعتماد وتطبيق أنظمة الإنتاج الصحيحة؛ إعداد تقييم للأداء من أجل تحقيق النقاج إستمر ارية النمو ؛ • • إعمج التكاليف و الفوائد البيئية الإجمالية.

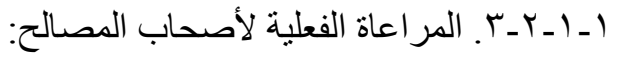
وعلى أساس هذه النقطة، تكون المؤسسة مسؤولة بيئيا إذا

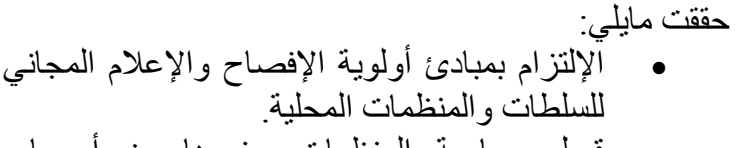

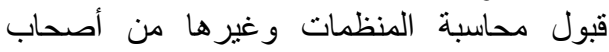
المصالح على مسؤولياتها البيئية الماضية، الحاضرة الحينة و المستقبلية. الإلتزام بشفافية الإفصاح عن نتأثيراتها البيئية الحقيقية. تقديم التقارير الدورية لأصحاب المصالح حول تأثير انها البيئية الحقيقية.

I-1 Tياسات ونظم الإدارة البيئية في منظمات الأعمال

يعتمد نظام حماية البيئة على العديد من الإجر اءات و التصرفات التي تسمح لها بتادية مهمتها في المحافظة على البئة البيئة على أكمل التهل

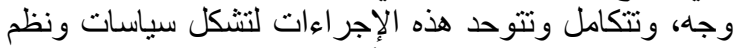

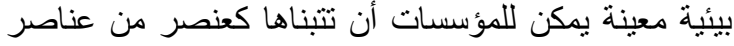
سياساتها الإنتاجية. وسنتطرق من خلال هذا العنصر إلى مفهوم 


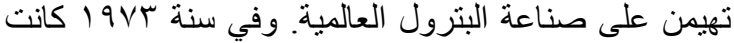

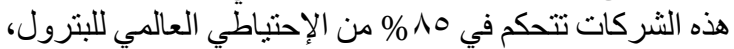

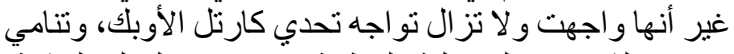

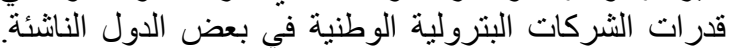
وتتمثل الثقيقات السبع في الشركات الترولة التالية:

شركة البترول الإنجليزية الفارسية الفية (المملكة

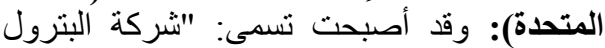

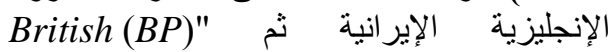
"Petoleum شركة نفط الخليج (الولايات المتحدة الأمريكية): في

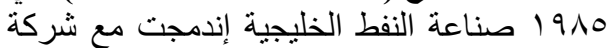

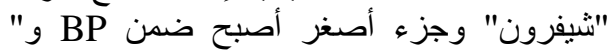

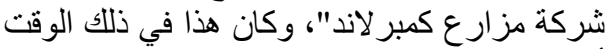

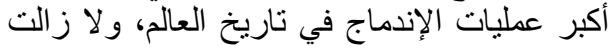

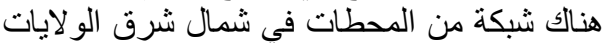
المتحدة تحمل هذا الإسم.

رويال دوتش شل Royal Dutch Shell

Standard oil of ستاندرد أويل أوف كالفورنيانة california (Socal) وأصبحت تسمى "شيفرون Chivron.

Standard Oil ستاندرد أويل أوف نيو جارزي و of New Jersey (Esso)

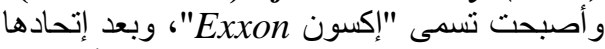
مع شركة "موبيل Mobil" سنة 999 19، أصبحت

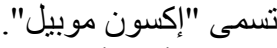

Standard Oil of ستاندرد أويل أوف نيويورئ دوبل New York (Sony) "أكسون" أصبحت تسمى: "موبيل"، و التي اتحدت مع شركة شركة تكساكو Texaco (الولايات المتحدة): و التي

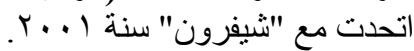
بالإضافة إلى هذه الثركات، فقد ظهرت التهرت في ميدان صناعة البترول بعض الثركات المتعددة الجنسيات ألتي حقفت فئت تقدما

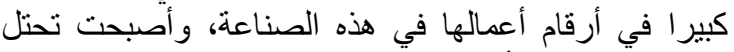

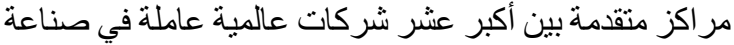

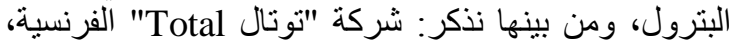

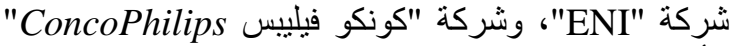
الأمريكية.

r ـ ـ ا المر احل التي مرت بها شركات البترول العالمية مرت أغلب هذه الثركات بخمسة مر احل حتى وصلت لوضعها الر اهن، نختصر ها فيما يلي: الثرهات

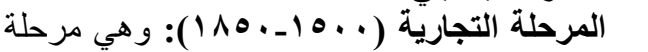

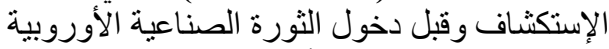
وحركة الإدارة العلمية بأمريكا، حيث كان الإنئ الإنتاج

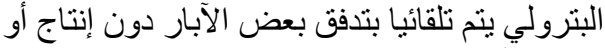
تنقيب علمي.

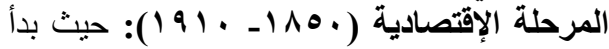

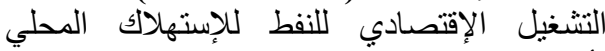
بأمريكا.

مرحلة حقوق الإمتياز بين الحربين العالميتين

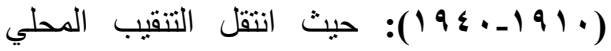

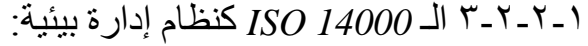

و هو معيار دولي واسع القبول لنظام الإدارة البيئية ويتكون من القن

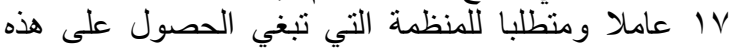
الثهادة، يمكن ذكر أهمها فيما يلي:

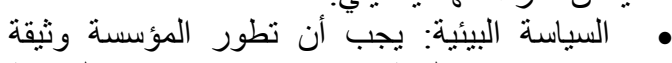

تعهدها نحو البيئة، ويجة البئب استخدام هذه السياسة كإطار للتخطيط و الفعل؛

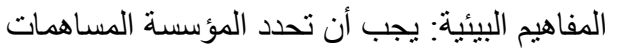

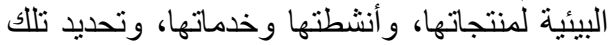
المساهمات التي لها آثار معنوية على الته البيئة؛

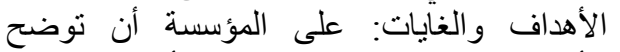

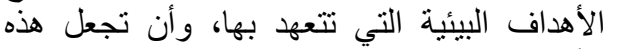
الأهداف و الإنطباعات و السياسات و الرؤي الروى البيئية

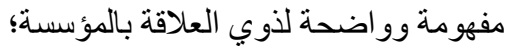

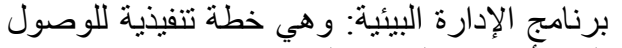

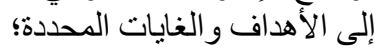

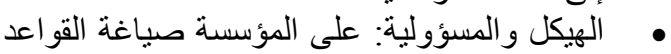
وتحديد المسؤوليات وتوفير المئي الموارد.

ץ. شركات البترول العالمية: قدر اتها واستر اتيجياتها

تعمل في قطاع البترول العالمي العديد من الثركات الكبيرة

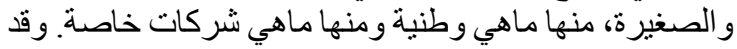

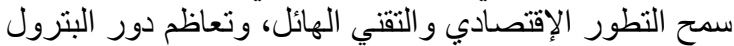
في الحضارة الحديثة بيروز بعض الإن الثركات العملاقة كمسيطرة

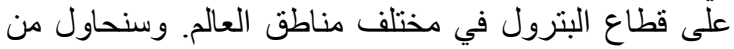
خلال هذا المحور التطرق إلى إبراز السمات الرئئيسية لهذهات

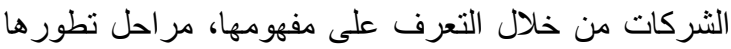
وأهم إستر اتيجياتها.

rـ ا شركات البترول العالمية: تعريفها ومر احل تطور ها

إن التطور المستمر في أداء هذه الثركات وزيادة أهمية الدور

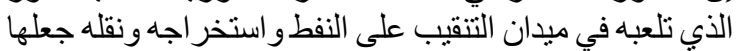
موضو عا للعديد من الأعمال الدر اسية التي تبحت التحث في مفهومها و قدر اتها و استر اتيجياتها.

$$
\text { بـ ا ـ ا التعريف بشركات البترول العالمية }
$$

تعرف الشركات النفطية الكبرى بأنها شركات متعددة

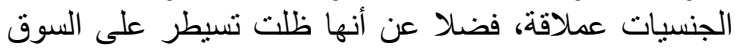

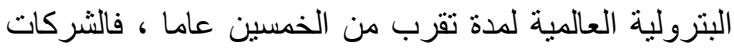

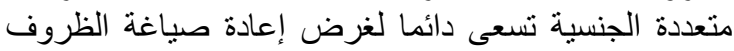

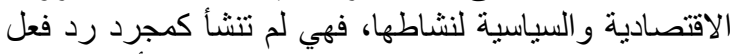

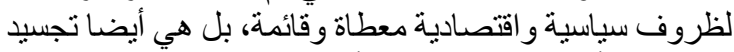

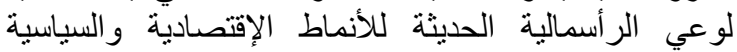

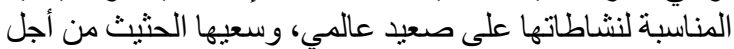

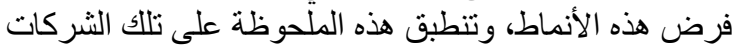

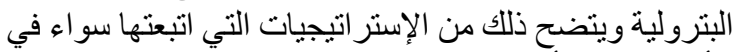
الأجل القصبر أو الطويل.

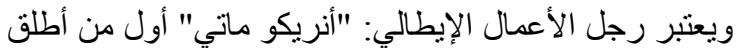

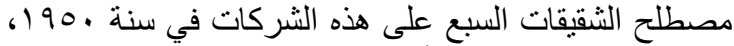

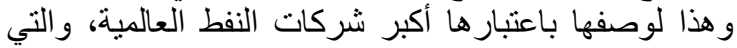


في هذا المجال واحتكارها خاصة في الدول

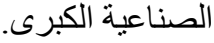

الطاقة الثمسية، حيث تمثل مجالا إستر اتيجيا للتوسع

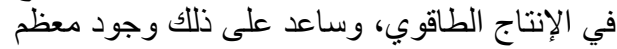

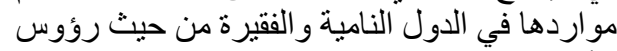

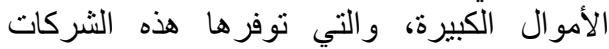
وبشروط تفرضها على الَّول المستقبلة لها. التنويع خارج نطاق الطاقة، و هذا من خلال إستثمار

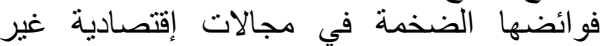
طاقوية، كالإستثمارات المالية والصناعية الغير

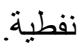

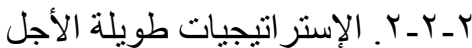

تتجلى الإستر اتيجيات الطويلة الأجل أساسا في السيطرة على السى

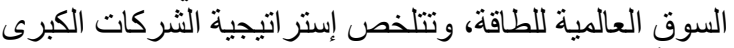
في الأجل الطويل في التحكم في تطور السوق العيلية العالمية للطاقة.

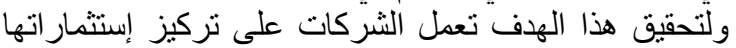

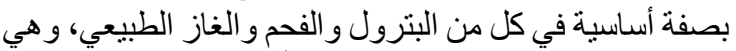

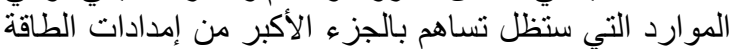

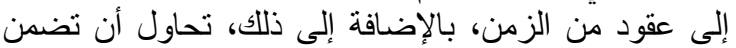

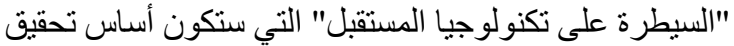
التوازن في السوق البترولية في الأجل الطويل .

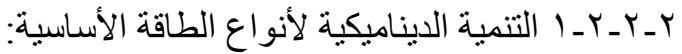

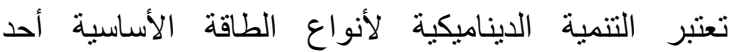

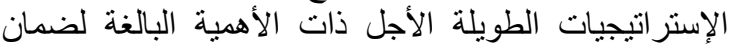
الشركات البترولية الكبرى مكانتها في السوق الدولية الألية ونجد فيها ما يلي: البترول، الفحم والغاز الطبيعي.

r Y_r_r_r T السبطرة التكنولوجية في الأجل الطويل

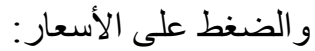

يعتبر التحكم في تكنولوجيا الطاقة التي يمكن أن نتطور في

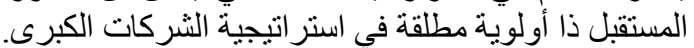

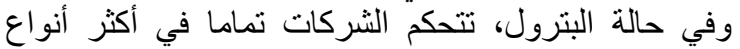
التكنولوجيا الحديثة تعقيدا وتكلفة بالنسبة لكل من الإستخر فئراج

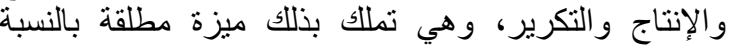

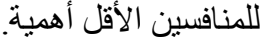
وفي نفس الوقت الذي تقدمت فيه الثركات في تكنولوجيا

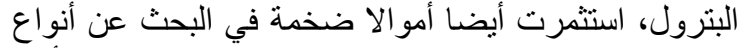
التكنولوجيا وطرق تتميتها لتوفير بدائل اللبترول في الأجل الني

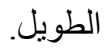
وينضح إذن أنه لاز ال للثركات البترولية الكبرى وزن كبير

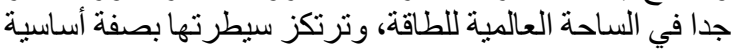
على ثلاثة عو امل وهي: قدر اتها المالية الكبيرة، و تنظيمها، وتحكمها في التكنولوجيًا.

rـ الآثار البيئية لنشاط شركات البترول العالمية ومسؤلياتها تجاه البيئة البئة

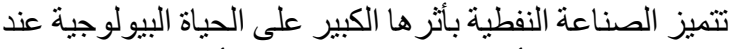

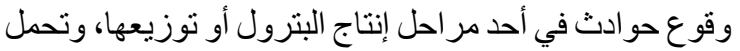
هذه الحو ادث الدول و الثركات النفطية تكاليف باهضة قد الند تكون
الأمريكي إلى النطاق الدولي عن طريق الحصول

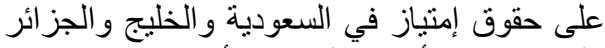
وليييا ومصر وأمريكا اللاتينية وأندونيسيا وليجيجية وليجيريا،

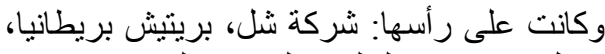
تونال في إيران و الخليج و العر اق و الجز ائر.

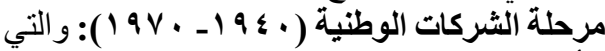

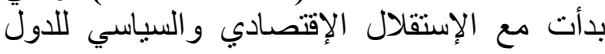

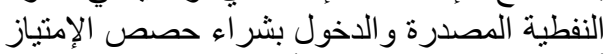
أو الششاركة في رؤوس الأمو ال و الإتجاه نحو إنثاء

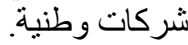

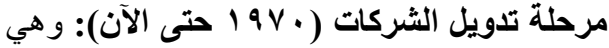

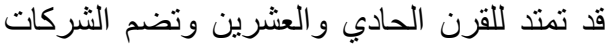

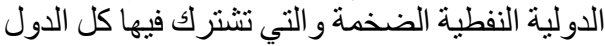

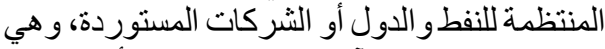

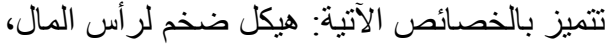
و وهيكل متنوع من القوى العاملة.

$$
\text { Y Y T إستر اتيجيات الشركات البترولية العالمية }
$$

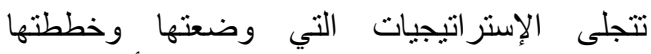

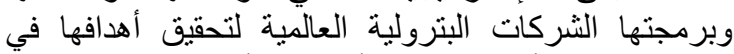

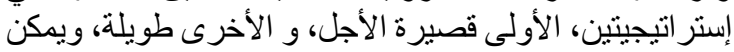

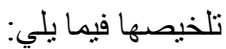

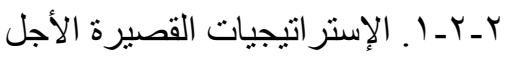
تتمثل الإستر اتيجيات القصيرة الأجل في استر اتيجيات أساسية، و أخرى مكملة، وهي كالآتي:

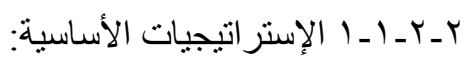

تتمثل الإستراتيجيات الأساسية في مواءمة الهياكل لتقلبات السوق البترولية، وهي كالآتي:

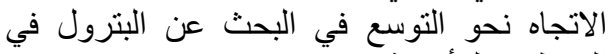
المناطق "المأمومة سياسيا".

الاتجاه نحو التوسع في البحث عن البترول في مناطق خارج دول الأوبك.

التلاؤم مع تطور الطلب على الألى المنتجات المكررة و وازدياد أهمية السوق الفورية.

التلاؤم مع التخفيض في النيوف درجة التورية التكامل الرأسي و السيطرة على المر احل اللاحقة في إنتاج البترول.

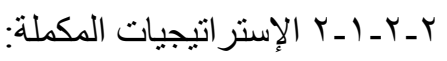

وتتميز الإستر اتيجية المكملة أساسا بالتتويع، حيث أدت أزمة إلتحة

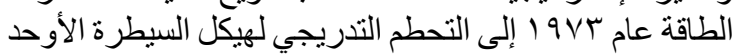

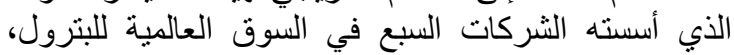

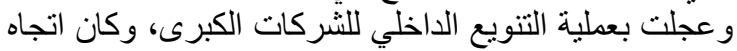

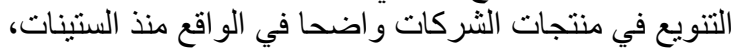

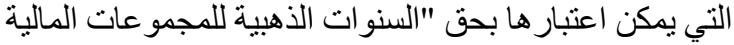

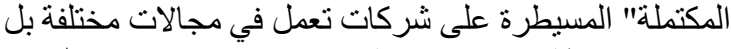

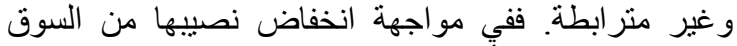
العالمية للبترول، بدأت الثركات في زيادة استخدام فو ائضها

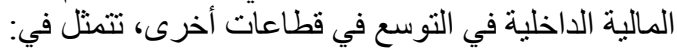
الطاقة النووية، وهذا من خلال توسيع إستثمار اتها 


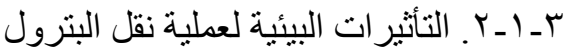

إن الإنفصال الدائم بين مواقع احتباطات النفط ومو اقع الحاجة

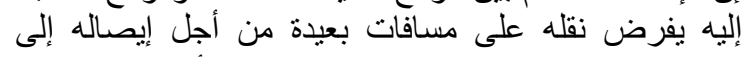

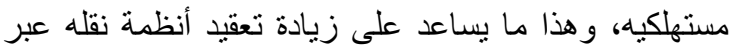

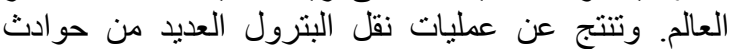

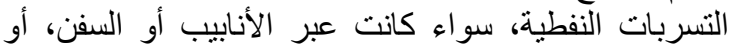

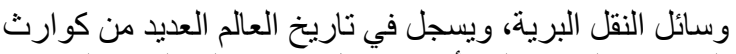

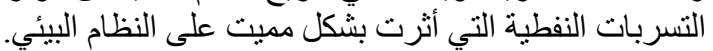

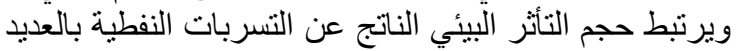

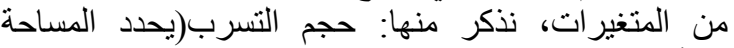
المتأثرة، وموقعها من الثناطئ)، نوع البترول، موسم التسرب،

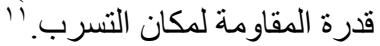
ويتأتى التلوثاث البحري الروتيني من عملية تنظيف الصهاريج

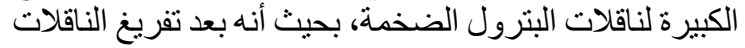

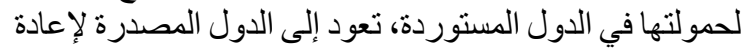

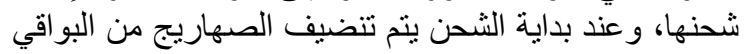

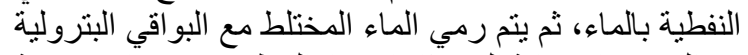

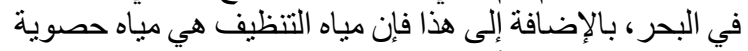

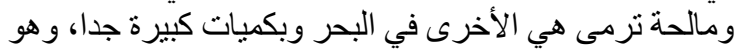

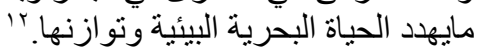

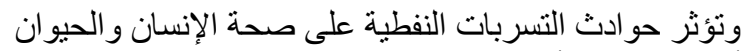

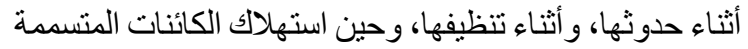

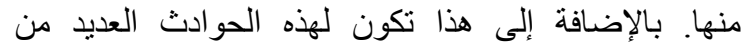

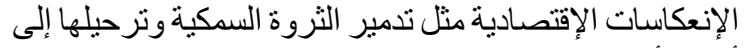

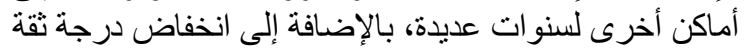
المستهلكين في سلامنها الصحية.

بــ T وجهة نظر شركات البترول العالمية لمسؤوليتها

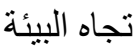

تعمل معظم شركات البترول العالمية على جعل أنشطتها

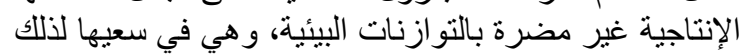
تقوم بتسطير إستر اتيجيات بيئية قصيرة وطوئية وليلة الأجل نلائم

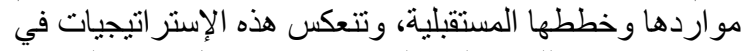

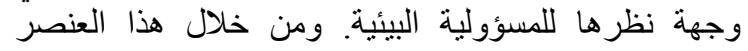

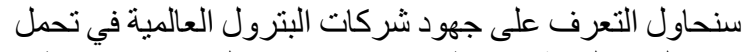
مسؤوليتها البيئية في إطار إستراتيجياتها المنفردة وفي إطار

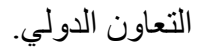

ك- بـ ا إستر اتيجيات شركات البترول العالمية لتحمل مسؤولياتها البيئية

تعتبر المسؤولية البيئية تحديا كبير ا بالنسبة للثركات البترولية

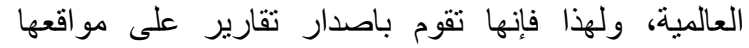
الإلكترونية حول معالم إستراتيجياتها لحماية النظام البيئي، و هذا من أجل ضمان ثقة المتعاملين فيها واستدامة إستثمار اتها

وأنشطتها المربحة.

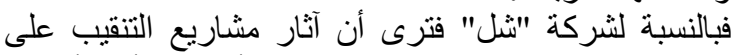
البترول و الغاز على الثروة البيئية والمائية أصبحت أكثان أكثر أهمية،

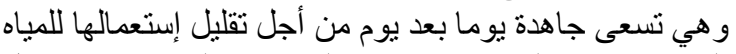

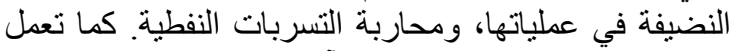

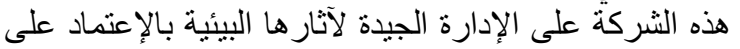

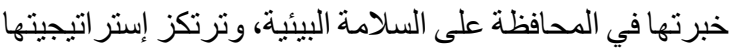

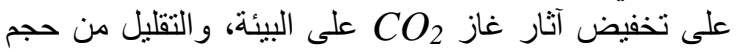

مادية أو غير مادية. و على الرغم من أن معظم شركات البترول

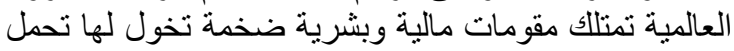

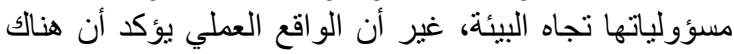

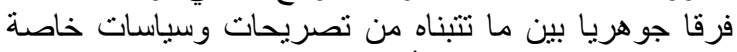

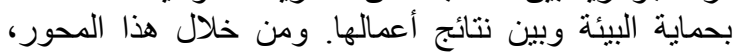

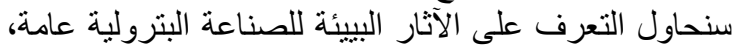
وكذا مدى احترام شركات البترول العالمية لمسؤولياتها تجاه لبناه

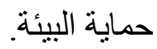

بـ ا الآثار البيئة للصناعة البترولية

تتميز الصناعة البترولية بتعقيد كبير في علاقاتها الفنية التي

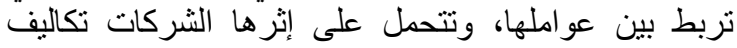

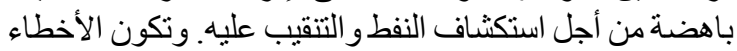

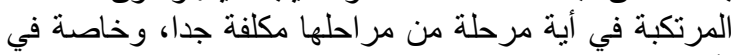

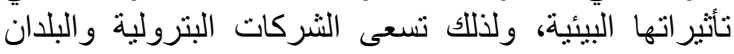

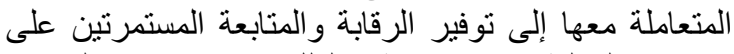

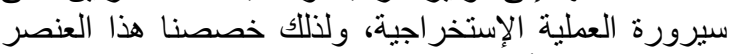

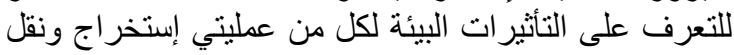

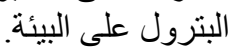

ـــ ا ـ ا التأثير ات البيئية لعملية إستكثاف النفط

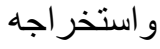

تؤثر عملية إستكثاف البترول واستخراجه بشكل كبير على الإنى

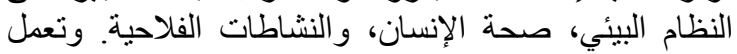
شركات البترول على البحث عن الإنيان والنترول باستخدام وسائل

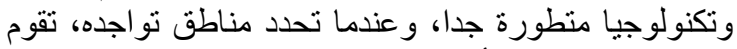
هذه الثركات بيناء الأرضيات و المضخات ولندات وإجر اء الإختبارات

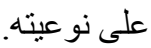

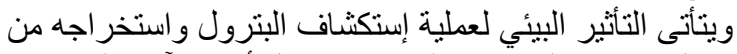

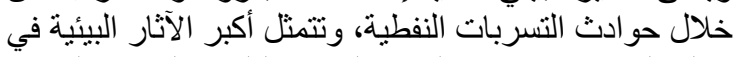

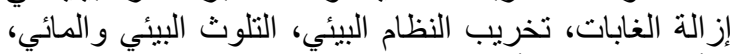

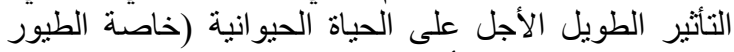

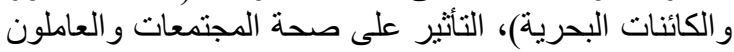
في الصناعة البترولية، و المساهمة في ترحيل الكائنات الحية.

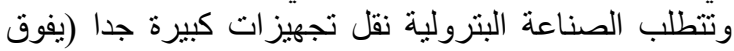

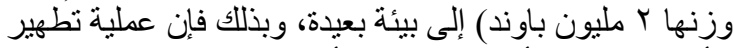

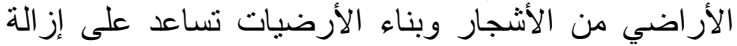

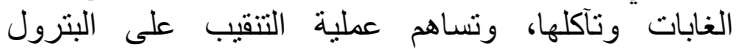

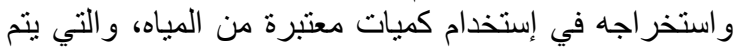

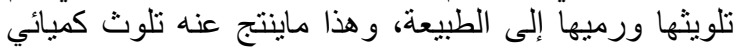
لالبيئة و المياه.

ويعتبر التلوث البحري من أهم صور تأثثير الصناعة البترولية

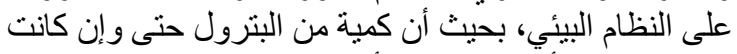

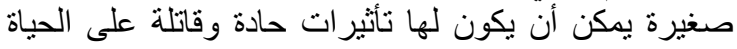

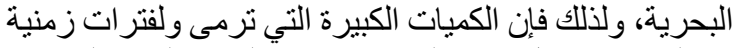

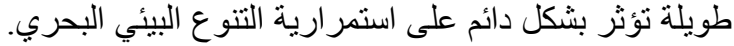

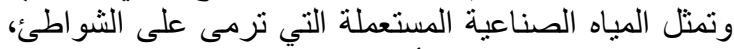

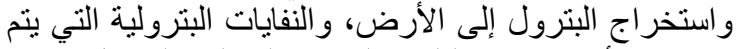
رميها من أهم مصادر التلوث البحري النتعلق بالبترول. 
حيث نعمل شركة "شل" بشر اكة مع المنظمات البيئية العالمبية

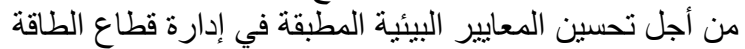

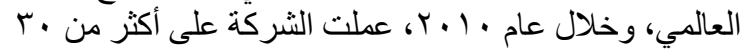
مشروعا مع الإتحاد الدولي للمحافظة على الطبيعة (IUCN)

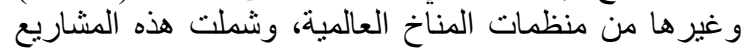

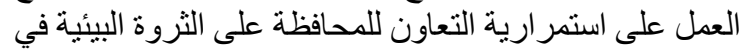

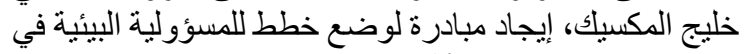
القطب المتجمد الثمالي. وبالنسبة لشركة BP فإنها تعمل مع العديد من الوكالات الدولية

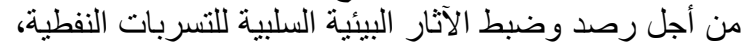

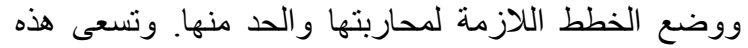
الثركة للتعلم من التجارب السابقة، وتطبيق الحلول اللازمة في هلي

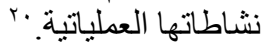

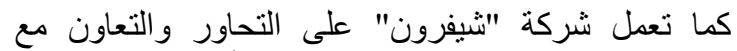

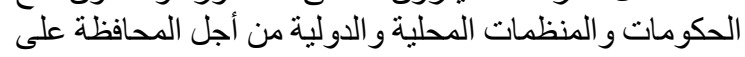

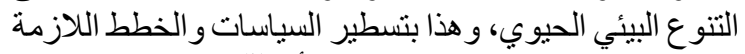
لتحمل المسؤوليات البيئية في هذا الثنأن." لتئيات

$$
\text { r-r حو ادث التسربات النفطية في العالم }
$$

تقوم شركات البترول العالمية بطر ح وجهة نظر ها فيما يخص تها

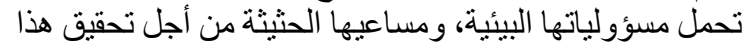

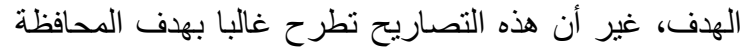

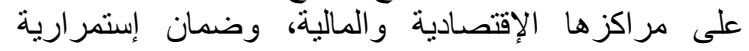

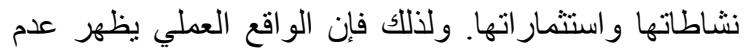

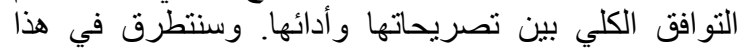

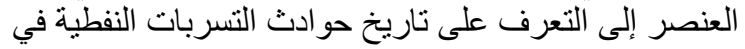
العالم، ومدى تحمل شركات البترول العالئرادية للمسؤولياتها

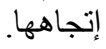

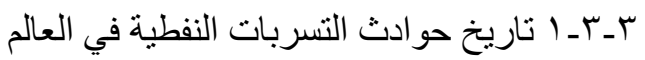

لقد سجل تاريخ العالم العديد من حوادث التسربات النفطية

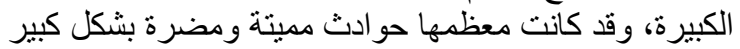

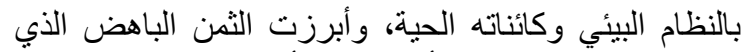

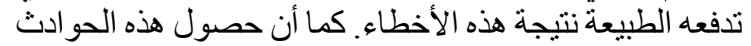

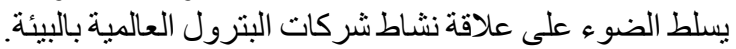

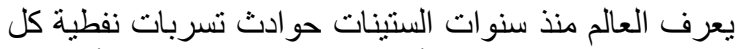

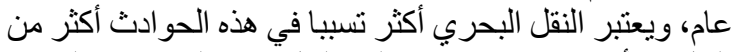

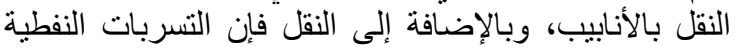

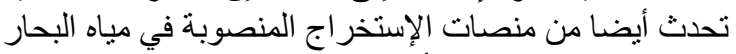

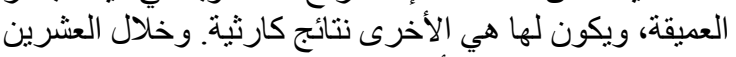

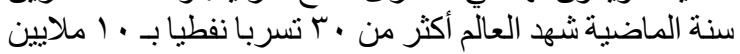

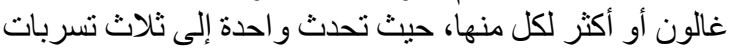

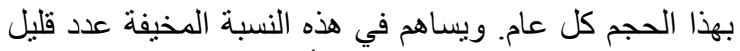

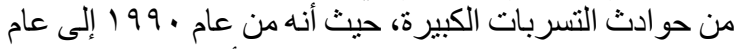

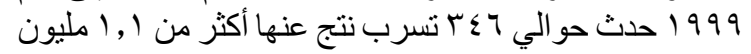

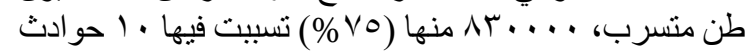
كبيرة فقط.

ويمكن تمثيل أكبر ، حوادث تسربات في العالم من خلال

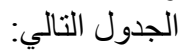

التسربات النفطية، وحماية مناطق البيئية الحساسة، و المحافظة

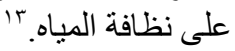
أما شركة "إكسون موبيل" فتعتبر أن حماية البيئية هي

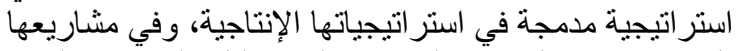

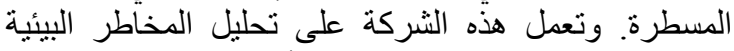

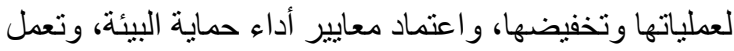

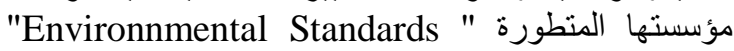
على إبراز أساسيات المسؤولية البيئية للششاريع في المناطق التي لم تصل إلى المفهوم الحقيقي لمسؤولية حماية البية البيئة،

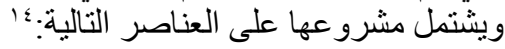

• إنبعاث أوكسيد الكبريت (VOCS . $\left(V O C_{S}\right)$

$$
\text { • • • • إنبعاث أوكسيد النيتروجين (NOC) }
$$

• • • • النفايات المضرة، و الإدارة البيئية و المائية.

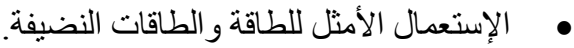

• • التأثير ات العملياتية على الأوساط البحرية.

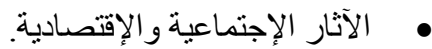

كما تعمل الثركة على تطوير أساليبها وسياساتها الإنية التي تساعدها

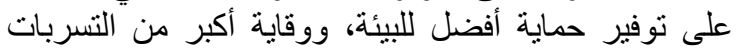
النفطية، حيث أنه على مدى الأربع سنو ات ات الأخيرة لم يحصل التهل

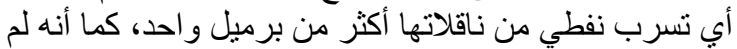

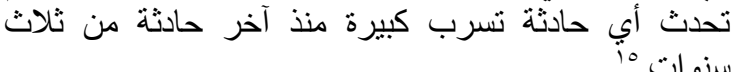
سنوات.

وبالنسبة لشركة BP فإنها تعمل على إدارة الآثار البيئية

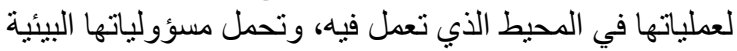

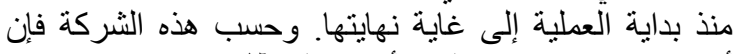

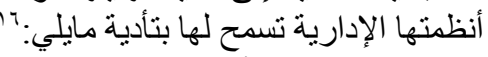

تحديد الآثار البيئية الفعلية لخططها ومشاريعها

$$
\text { الإستثمارية؛ }
$$

القيام بخطو ات فعالة من أجل الحد من هذه الآثار؛

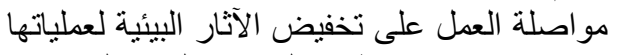

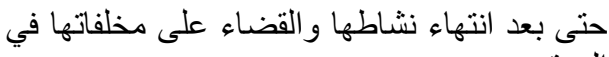

$$
\text { الموقع. }
$$

بالإضافة إلى هذا، تتوفر الثركة على استراتيجية من أجل

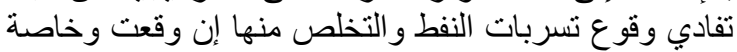

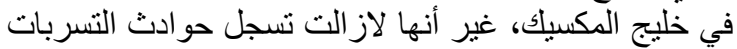

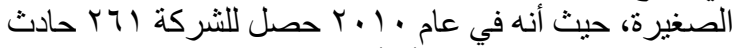

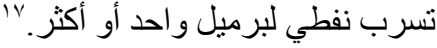

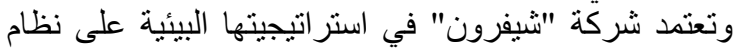

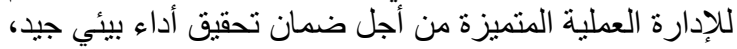
وقد نصت عملية تقييم الآثار البيئية والإجتماعية والئية الصحية الصية (ESHIA)

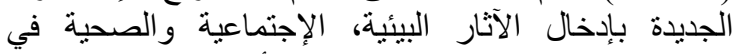

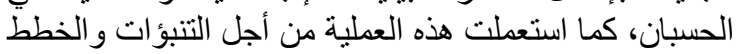

المستقبلية وتفادي وتندية آثنار ها السلبية.

$$
\text { بإ_r-r.r. المسؤولية البيئية لنركات البترول العالمية في }
$$

بالإضافة إلى الإستراتيجيات البيئية المنفردة لكل واحدة من لئن

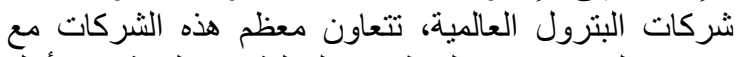

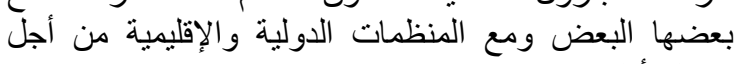

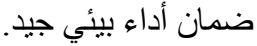


الجدول رقم (ץ)): أكبر عشرة حو ادث تسربات نفطية في العالم

\begin{tabular}{|c|c|c|c|}
\hline كمية التسرب (غالون) & السنة & الإسم & الترتيب \\
\hline $240,000,000$ & 1991 & Perisian gulf: tankers, pipelines and terminals, offshore Saudi Arabia. & 1 \\
\hline $140,000,000$ & $191 \cdot-19 \vee 9$ & Istoc I oil well, Ciudad del Carmen, Mexico. & r \\
\hline $80,000,000$ & 1914 & Nowruz field, Perisian Gulf. & $r$ \\
\hline $80,000,000$ & 1994 & Fergana oil well, Uzbekistan. & $\varepsilon$ \\
\hline $78,500,000$ & 1914 & Castillo de Bellver tanker, offshore Cape Town, South Africa. & 0 \\
\hline $68,670,000$ & $19 \vee 1$ & Amoco Caldiz, tanker, offshore Brittany. & 7 \\
\hline $48,800,000$ & $19 \vee 9$ & Aegean Captain tanker, offshore Tobago. & $\mathrm{V}$ \\
\hline $42,000,000$ & 191. & Production well D-103, Tripoli, Libya. & $\wedge$ \\
\hline $36,600,000$ & 191. & Irenes Serenade tanker, Pilos, Greece. & 9 \\
\hline $31,170,000$ & 1911 & Kuwait storage tanks. & $1 \cdot$ \\
\hline
\end{tabular}

مهمة في العالم، وتتواجد فيها وتحتكر إستثمارات التنقيب

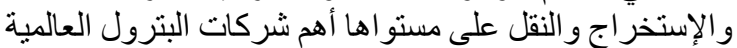

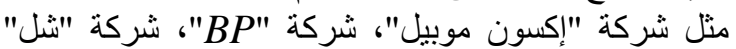

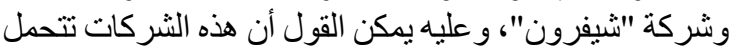

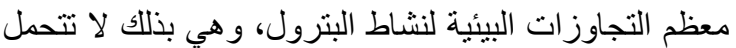

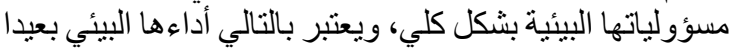

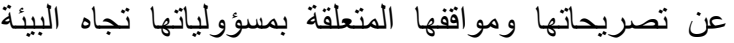

العاملة فيها.

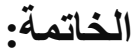

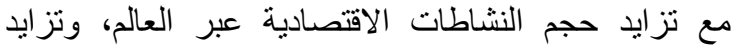
الاحتياجات الاستهلاكية النهائية و الوسيطية بالتبعية، فقد أصبح الصبح

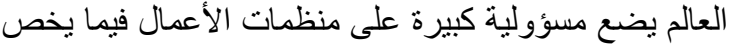

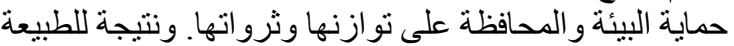

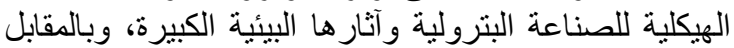

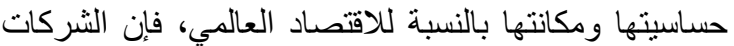

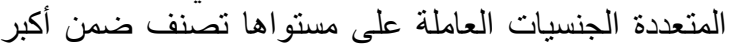

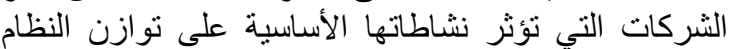

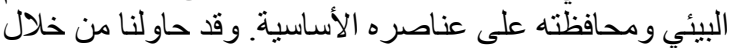

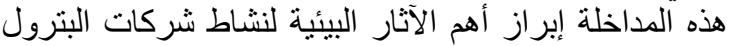

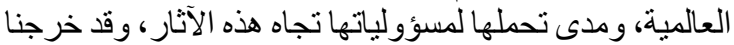
بالنتائج التالية:

تمثل المسؤولية البيئية عنصر ا مهما من عناصر

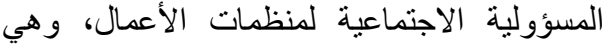

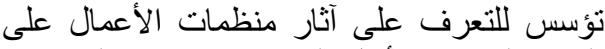

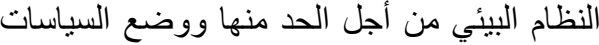
والنظم الإسنر اتيجية الكفيلة بذلك. تعتبر شركات البترول العالمية شركات متعددة

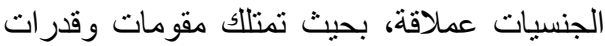

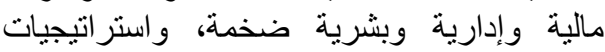

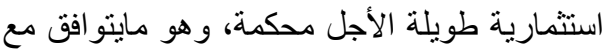
طبيعة الصناعة العاملة فيها واحتياجاتها. تسمح الطبيعة الهيكلية للصناعة البترولية بوجية الصود

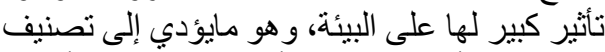

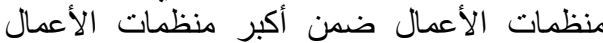

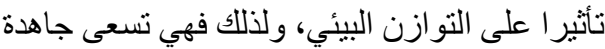

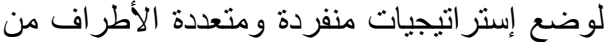

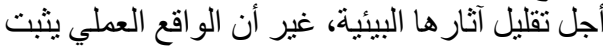

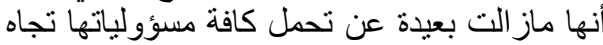

يتضح من هذا الجدول أن أكبر حوادث التسربات النفطية هي

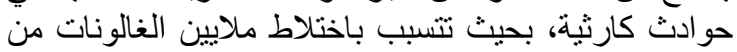

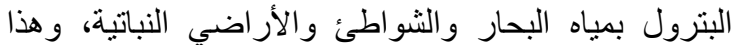
مايؤدي إلى التأثير الحاد على النظام البيئي. حيث النئ أن أكبر هذانه

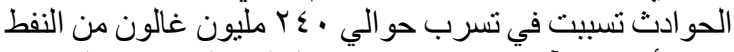

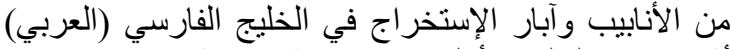

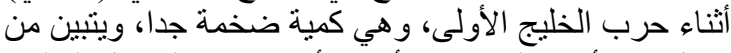

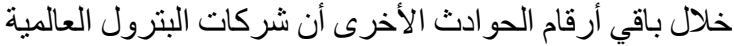

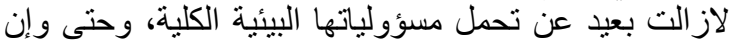

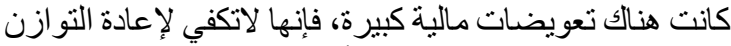

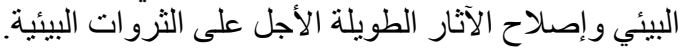

$$
\text { r_r_r مناطق حدوث التسربات النفطية في العالم }
$$

تتوزع حوادث التسربات النفطية عبر مختلف مناطق العالم

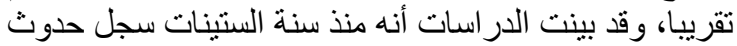

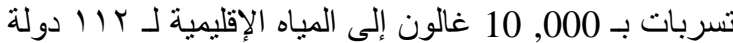

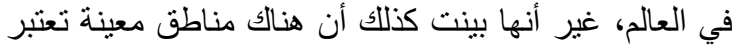

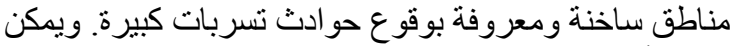

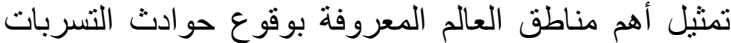
النفية في الجدول النالي:

\begin{tabular}{|c|c|}
\hline الحوادث & المنطقة \\
\hline rTV & خليج المكسيك \\
\hline Is. & شمال شرق الو لايات المتحدة الأمريكية \\
\hline ITV & البحر الأبيض المتوسط \\
\hline $1 \cdot 1$ & الخليج الفارسي \\
\hline Vo & بحر الشمال \\
\hline 7. & | اليابان \\
\hline or & بحر البلطيق \\
\hline$\sum 9$ & المملكة المتحدة \\
\hline rq & ماليزيا وسنغافورة \\
\hline זr & الإسبانية الجنوبي لفرنسا/ شمال وجنوب السواحل \\
\hline rr & كوريا \\
\hline
\end{tabular}

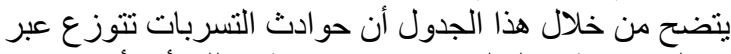

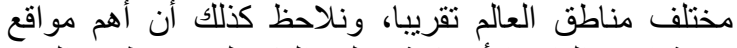

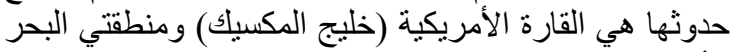

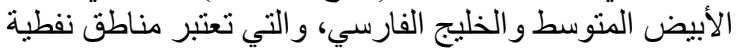


Alison JAMISON, Marlo RAYNOLDS, Peggy

HOLROYD, Erik VELDMAN, Krista TREMBLETT: Defining corporate environmental responsibility. Canadian ENGO .perspectives, October 2005, P07

Alison JAMISON, Marlo RAYNOLDS, Peggy

HOLROYD, Erik VELDMAN, Krista .TREMBLETT, P08

ياسر شاهين:البعد البيئي للمسؤولية الاجتماعية للقطاع الخاص الاصنية

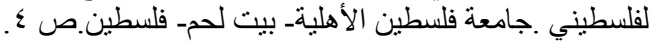

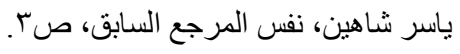

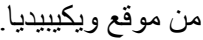

Dara O'ROURK, Sarah CONNOLLY: Just oil ? The distribution of environmental and social impacts of oil production and consumption. .Annual Reviews, 2003, P594

Dara O'ROURK, Sarah CONNOLLY, OP-SIT, .P601

Sandra KLOFF, Clive WICKS : Gestion environnementale de l'exploitation de pétrole offshore et du transport maritime pétrolier. Un document d'information à l'attention des parties prenantes de l'écorégion marine ouest africaine,

.CEESP, Octobre 2004, P24

Royal Dutch Shell PLC Sustainability report 2010,

.P5

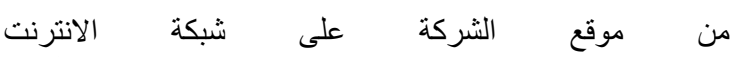

WWW.ExxonMobil.com r. $11 / 1, r / r$

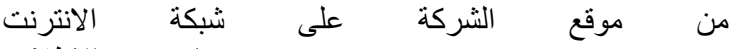
WWW.ExxonMobil.com $r+11 / T / r r$

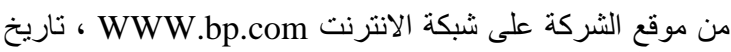

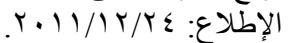

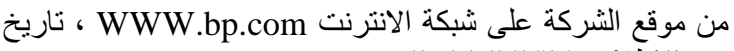

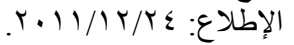

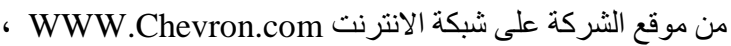

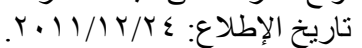

Royal Dutch Shell PLC Sustainability report 2010,

.P5

من موقع الثركة على شبكة الانترنت WWW.bp.com ، إناريخ

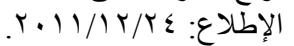

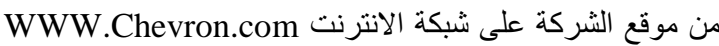

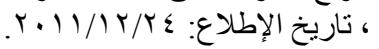

Dara O'ROURK, Sarah CONNOLLY, OP-SIT, .P599

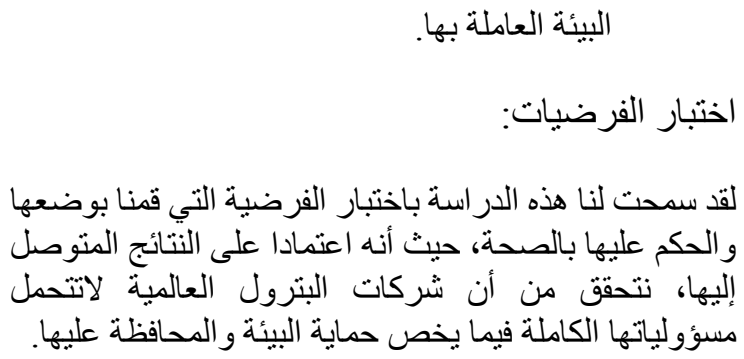

لقد سمحت لنا هذه الدر اسة باختبار الفرضية التي قمنا بوضعها

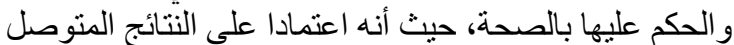

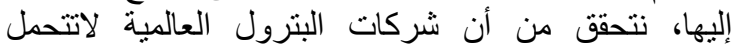
مسؤولياتها الكاملة فيما يخص حماية البيئة و المحافظة عليها.

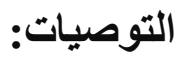

من خلال الدارسة التي قمنا بها و النتائج التي خرجنا بها، فإنها يمكننا في الأخير إدراج بعض الأي التوصيات المتعلقة بالموضوع

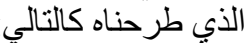

تعتبر المسؤولية البيئية لمنظمات الأعمال مسألة

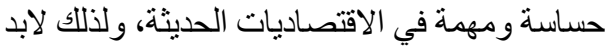
من العمل على تحسيس منظمات الأعمال باتخاذها لإنها

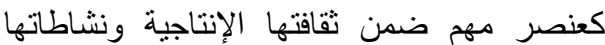
الاقتصادية الطويلة و القصيرة الأجل.

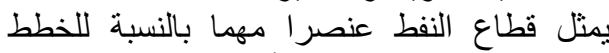
الاقتصادية لكل دولة، غير أن آثاره البيئية الكبيرة

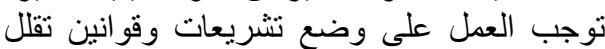
منها، وتحد من التجاوزات البيئية لشركات البترولت البرول تفرل

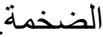

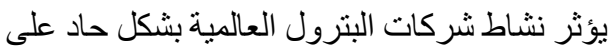
مكونات النظام البيئي، إلا أن مكانتهات العئه وأهميتها

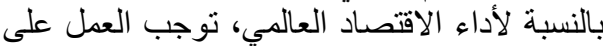

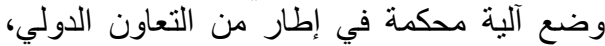
تسمح لها بالمساهمة في رفع معدلات في المات النمو العالمية، وبالمقابل تساهم في زيادة معدل كفاءة أداءها البيئي.

\section{المراجع}

Porter MAZURKIEWICZ: Corporate environmental responsibility: Is a common CSR farmework possible? DevComm-SDO, World .bank, P07 من موقع ويكيبيديا.

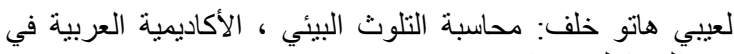

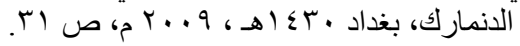

ENVIRONMENTAL

RESPONSIBILITY, www.johnsabella.com/pdfs/EnvironmentalResp .onsibility.pdf , Date de vu: 16-12-2011, P60 